\title{
Effect of Chemical Denture Disinfectants and Tree Extracts on Biofilm-forming Staphylococcus aureus and Viridans Streptococcus Species Isolated from Complete Denture
}

\author{
Leoney Andonissamy ${ }^{1}$, Suma Karthigeyan ${ }^{2}$, Seyed A Ali ${ }^{3}$, John W Felix ${ }^{4}$
}

\begin{abstract}
Aims: The present study aims at recording the antibacterial efficacy of various disinfectants used at different time periods against Staphylococcus aureus and viridans streptococcal species of bacteria isolated from complete dentures.

Materials and methods: Fifty complete denture patients were selected for the study and swabs were collected from their complete denture surfaces. The isolated bacteria were subjected to six experimental groups which includes four groups of chemical denture disinfectants and two tree extracts groups. Isolation of the bacteria $S$. aureus and viridians streptococcal species was done by means of selective media and confirmed by means of biochemical tests. The bacteria were subjected to biofilm assays. The biofilm-forming bacteria with optical density (O.D.) values of more than 1.5 were selected for the study. About 150 acrylic specimens were fabricated and were contaminated by the 2 isolated bacteria mentioned above. The contaminated samples were disinfected by immersion for 10, 20, and 30 minutes in six disinfectants, namely: (1) 1\% sodium hypochlorite, (2) $2 \%$ chlorhexidine, (3) $2 \%$ glutaraldehyde, (4) $3.8 \%$ sodium perborate, (5) $2 \%$ aalam extract, and (6) $2 \%$ neem extract. Results: ANOVA test was performed for both $S$. aureus and viridans streptococcal species with regard to various synthetic and tree extracts as well as time duration of disinfection. F values for disinfection vs $S$. aureus is $205.4(p<0.001)$ and the relevant Scheffe post hoc test values is in the following order: $3<1,4<6,2<5$. F values for disinfection vs viridans streptococcal species is $364.7(p<0.001)$ and the relevant Scheffe post hoc test values is in the following order: $3<4<1,6,2<5$.

Conclusion: For biofilm-forming S. aureus, $2 \%$ glutaraldehyde showed best antibacterial efficacy which was followed by $1 \%$ sodium hypochlorite and $3.8 \%$ sodium perborate. When it comes to biofilm-forming viridans streptococcal species, $2 \%$ glutaraldehyde showed best antibacterial efficacy. Next to $2 \%$ glutaraldehyde, $3.8 \%$ sodium perborate exhibited good disinfection potential.

Clinical significance: Complete denture patients have a plethora of microorganisms habitating their complete dentures. Some bacteria are capable of causing systemic illness such as aspiration pneumonia and endocarditis. Hence, constant removal and disinfection of biofilms from the denture surface is vital to the local and systemic wellness of the patient. The most common bacteria capable of causing pneumonia and endocarditis that are isolated from complete dentures include $S$. aureus and viridans streptococcal species. The present study evaluates antibacterial efficacy of different disinfection agents especially against these biofilm-forming bacteria for different time periods.
\end{abstract}

Keywords: Biofilms, Denture disinfectants, Laboratory research, Plant-based disinfectants, Staphylococcus aureus, Viridans Streptococcus.

The Journal of Contemporary Dental Practice (2019): 10.5005/jp-journals-10024-2712

\section{INTRODUCTION}

Dentures are prosthetic medical devices that create an appropriate habitat for a variety of microorganisms especially bacteria. These bacteria form biofilms on the denture surface, which mature and dissipate free planktonic bacteria into the body system. These free planktonic bacteria are capable of causing systemic infections namely endocarditis and pneumonia. Hence, these biofilms have to be frequently removed and disinfected from the denture surface ${ }^{1}$ to prevent the maturation of the biofilms as well as the dissipation of the bacteria to local and distant organs in order to avert systemic infections.

The biofilms have an added advantage of being resistant to many synthetic disinfectants due to the presence of exopolysaccharide layer around them, which acts as a barrier against the action of disinfectants. Hence, it is imperative for the complete denture patients to remove the biofilms formed on the denture surface as well to disinfect the dentures for the purpose of their local and systemic wellness.

The common denture disinfectants used include sodium perborate, sodium hypochlorite, chlorhexidine gluconate, and glutaraldehyde. These denture disinfectants have different modes of action.
${ }^{1}$ Department of Dental Materials, Rajah Muthiah Dental College and Hospital, Annamalai University, Chidambaram, Tamil Nadu, India

2,3 Department of Prosthodontics and Crown and Bridges, Rajah Muthiah Dental College and Hospital, Annamalai University, Chidambaram, Tamil Nadu, India

${ }^{4}$ Department of Community Medicine, Rajah Muthiah Medical College and Hospital, Annamalai University, Chidambaram, Tamil Nadu, India

Corresponding Author: Leoney Andonissamy, Department of Dental Materials, Rajah Muthiah Dental College and Hospital, Annamalai University, Chidambaram, Tamil Nadu, India, Phone: +91 9790580225, e-mail: antony.leoney@gmail.com

How to cite this article: Andonissamy L, Karthigeyan S, Ali SA, et al. Effect of Chemical Denture Disinfectants and Tree Extracts on Biofilm-forming Staphylococcus aureus and Viridans Streptococcus Species Isolated from Complete Denture. J Contemp Dent Pract 2019;20(11):1307-1314.

Source of support: Nil

Conflict of interest: None

Sodium hypochlorite directly acts on organic matrix of plaque causing dissolution of polymer structure. ${ }^{2,3}$ Chlorhexidine has both bacteriostatic and bactericidal properties. The primary site of

() The Author(s). 2019 Open Access This article is distributed under the terms of the Creative Commons Attribution 4.0 International License (https://creativecommons. org/licenses/by-nc/4.0/), which permits unrestricted use, distribution, and non-commercial reproduction in any medium, provided you give appropriate credit to the original author(s) and the source, provide a link to the Creative Commons license, and indicate if changes were made. The Creative Commons Public Domain Dedication waiver (http://creativecommons.org/publicdomain/zero/1.0/) applies to the data made available in this article, unless otherwise stated. 
action is the cytoplasmic membrane, with resulting modification of membrane permeability. ${ }^{4,5}$ Glutaraldehyde acts by denaturing proteins and by alkylating nucleic acids. ${ }^{5} 0.5 \%$ sodium hypochlorite and coconut soap have been found to reduce $S$. mutans as well as the development of biofilm on the denture surface. ${ }^{6}$

The present study investigates the antibacterial efficacy of different synthetic and plant-derived denture disinfectants on biofilm-forming S. aureus and viridans Streptococcus isolated from complete denture patients. The reason for inclusion of plantderived denture disinfectant is to analyze the natural alternatives to synthetic disinfectants that are by virtue capable of causing detrimental effects to prosthesis and denture wearers.

\section{Inclusion Criteria}

Complete denture patients who were wearing complete dentures at least for the past 6 months and who are healthy (i.e., with no systemic diseases) were included in the study. Only patients who were willing to participate in the study and who gave consent to collect saliva/denture plaque samples were included in the study.

\section{Exclusion Criteria}

Patients with chronic systemic diseases and who were on medications were excluded from the study. Patients who have used antibiotics within 30 days prior to sample collection were also excluded from the study. Patients who had smoking habit were also excluded.

\section{Sample Collection}

Complete edentulous patients ( $n=30$ patients) who are wearing complete dentures at least for the past 6 months were selected for the study. A sterile swab (Hiculture Transport Swab, Himedia, Mumbai, India) was used to collect samples from patient's oral cavity as well as from all over the complete denture's surface. The swab was subjected to microbiological investigation in the laboratory.

\section{Isolation of Bacteria}

Selective media were obtained from Himedia Laboratories, Mumbai, India, and they were prepared and sterilized using autoclave and poured in petriplates. The selective media used for S. aureus is Mannitol salt agar (HiChrome Staph Agar, Lot number: 0000112805) and the selective media used for viridians Streptococcus species is Mutans-Sanguis Agar (Mutans-Sanguis Agar, Lot number: 0000237969).

\section{Procedure}

About $10 \mu \mathrm{L}$ of each sample was inoculated in sterile selective media plates by spread plate using $L$ spreader and incubated at $37^{\circ} \mathrm{C}$ for 24 hours initially. The plates were observed for changes until 48 hours. Based on colony morphology, the colonies were selected and inoculated on sterile nutrient agar plate by quadrant streaking. Around 10 colonies were detected and pure isolates were obtained and further Gram's stained.

\section{Gram's Staining}

The pure isolate was smeared in a slide and stained using Gram's stain kit (Himedia Mumbai, India, Lot number: 0000187211). The stained slide was observed under $100 \times$ oil immersion objective using bright field microscope to study the morphology. Based on similar characteristics in Gram's staining, 20 organisms (10 Streptococcus and 10 S. aureus) were selected and biochemical tests were done to confirm the microorganism.

\section{Biochemical Test}

Biochemical tests were selected based on the characters identified from selective media and Gram's staining. Tests like indole, methyl red, Voges Proskauer, citrate utilization, triple sugar iron agar, blood agar, carbohydrate fermentation test, catalase, and coagulase test were used as required by the organism to be identified.

\section{Microtiter Plate Assay for Biofilm Quantification}

S. aureus and viridans streptococcal species biofilms were formed on pre-sterilized 12 well flat bottom polystyrene microtiter plates. Briefly, a $10 \mu \mathrm{L}$ of cell suspension having 0.5 optical density (O.D.) 600 was inoculated in $190 \mu \mathrm{L}$ trypticase soy broth (TSB) medium in each well and $200 \mu \mathrm{L}$ of autoclaved distilled water was added in peripheral wells as controls. Then microtiter plates were incubated for 16 hours at $37^{\circ} \mathrm{C}$. After aspiration of planktonic cells, biofilms were fixed with $99 \%$ methanol. Plates were washed twice with phosphate buffer saline and air-dried.

Then, $200 \mu \mathrm{L}$ of crystal violet solution (0.2\%) was added to all the wells. After 5 minutes, the excess crystal violet was removed and plates were washed twice and air dried. Finally, the cell-bound crystal violet was dissolved in $33 \%$ acetic acid. Biofilm growth was monitored in terms of O.D. $570 \mathrm{~nm}$ using micro-plate reader (Multiskan, Thermo Fisher Labsystems, United States). The strains with optical density readings above 1.5 were selected for the disinfection study as they showed excellent biofilm-forming abilities (Tables 1 and 2).

Among the 10 isolates, only 6 strains of S. aureus and 6 strains of viridans Streptococcus species which had O.D. values more than 1.5 were selected.

\section{Disinfection Procedure}

\section{Materials}

The culture media used for the study included nutrient broth (NB) and nutrient agar (NA).

The disinfectants used included the following:

Sodium hypochlorite (1\%), chlorhexidine (2\%), glutaraldehyde (2\%), sodium perborate (3.8\%), neem bark extract (Azadirachta indica, 2\%), and aalam prop root extract (Ficus benghalensis, 2\%), and saline $(0.9 \%$ sodium chloride in distilled water) were used as control.

The rationale for using these concentration of individual disinfectants is usage of minimal concentrations of the disinfectant to achieve optimum disinfection keeping in mind two important factors, namely:

- Minimal damage to the prosthesis due to disinfection procedure.

- Avoidance of local/systemic side effects of residual disinfectants on denture base acrylic surface.

\section{Fabrication of Acrylic Strips}

One hundred and fifty denture base acrylic resin strips were fabricated by means of wax patterns with the dimensions as length $50 \mathrm{~mm}$, width $10 \mathrm{~mm}$, and thickness $2 \mathrm{~mm}$. The wax samples were prepared using custom-made metal molds. The wax strips were then invested in dental flasks with type III gypsum product, i.e., dental stone, and dewaxing was done. The heat cure acrylic resin was prepared with polymer:monomer ratio of 3:1 by volume in a mixing jar by using the measuring cylinder. The stone mold was packed in dough stage. Polymerization of acrylic resin was done following a short curing cycle $\left(74^{\circ} \mathrm{C}\right.$ for 2 hours followed by terminal boiling for 1 hour) in acrylizer. After curing, overnight bench cooling was done. The cured samples were deflasked carefully, and finishing was done. 
Table 1: Biofilm optical density values for Staphylococcus aureus

\begin{tabular}{|c|c|c|c|c|c|c|c|c|c|c|}
\hline $\begin{array}{l}\text { Staphylococcus } \\
\text { aureus }\end{array}$ & & & & Colum & umbers $(r$ & $n \pm$ stanc & deviatio & & & \\
\hline \multirow{2}{*}{$\begin{array}{l}\text { Optical density } \\
\text { values (OD) }\end{array}$} & 1 & 2 & 3 & 4 & 5 & 6 & 7 & 8 & 9 & 10 \\
\hline & $\begin{array}{l}0.57 \\
( \pm 0.31) \\
\end{array}$ & $\begin{array}{l}0.77 \\
( \pm 0.25)\end{array}$ & $\begin{array}{l}1.11 \\
( \pm 0.84) \\
\end{array}$ & $\begin{array}{l}1.48 \\
( \pm 1.44) \\
\end{array}$ & $\begin{array}{l}1.50 \\
( \pm 1.27) \\
\end{array}$ & $\begin{array}{l}1.52 \\
( \pm 1.09) \\
\end{array}$ & $\begin{array}{l}1.56 \\
( \pm 0.99) \\
\end{array}$ & $\begin{array}{l}1.57 \\
( \pm 1.10) \\
\end{array}$ & $\begin{array}{l}1.59 \\
( \pm 1.39) \\
\end{array}$ & $\begin{array}{l}1.66 \\
( \pm 1.19) \\
\end{array}$ \\
\hline
\end{tabular}

Table 2: Biofilm optical density values for viridans Streptococcus

\begin{tabular}{|c|c|c|c|c|c|c|c|c|c|c|}
\hline $\begin{array}{l}\text { Viridans Streptococcus } \\
\text { species }\end{array}$ & Column & mbers (me & \pm standa & deviation) & & & & & & \\
\hline \multirow{2}{*}{$\begin{array}{l}\text { Optical density } \\
\text { values (OD) }\end{array}$} & 1 & 2 & 3 & 4 & 5 & 6 & 7 & 8 & 9 & 10 \\
\hline & $\begin{array}{l}0.85 \\
( \pm 0.20)\end{array}$ & $\begin{array}{l}1.51 \\
( \pm 0.23)\end{array}$ & $\begin{array}{l}1.52 \\
( \pm 0.26)\end{array}$ & $\begin{array}{l}0.95 \\
( \pm 0.28)\end{array}$ & $\begin{array}{l}1.54 \\
( \pm 0.38)\end{array}$ & $\begin{array}{l}1.50 \\
( \pm 0.52)\end{array}$ & $\begin{array}{l}1.50 \\
( \pm 0.35)\end{array}$ & $\begin{array}{l}1.53 \\
( \pm 0.22)\end{array}$ & $\begin{array}{l}1.16 \\
( \pm 0.09)\end{array}$ & $\begin{array}{l}0.98 \\
( \pm 0.37)\end{array}$ \\
\hline
\end{tabular}

\section{Materials and Methods}

The acrylic strips used for respective experiments were sterilized using autoclave.

Step I: the inoculums for biofilm formation were prepared by inoculating the bacteria in sterile nutrient broth and incubated at $37^{\circ} \mathrm{C}$ overnight.

Step II: further, $1 \mathrm{~mL}$ of the overnight bacteria laden nutrient broth was adjusted to 0.5 McFarlands Standards and was inoculated on the sterile acrylic strip. This was kept for incubation at $37^{\circ} \mathrm{C}$ overnight.

Step III: after the incubation period, the acrylic strips were rinsed with sterile distilled water gently and transferred into a tube containing different disinfectants for different time durations (i.e., 10,20 , and 30 minutes, respectively). The acrylic strip containing the disinfectant is again transferred into the sterile tube containing nutrient broth after the holding time with the disinfectant. A control tube containing sterile saline alone (without disinfectant) was kept to predict the initial bacterial population in the biofilm. For each disinfectant and the different time durations (10,20, and 30 minutes), separate tubes were used.

Step IV: the acrylic strip in sterile nutrient broth was agitated vigorously to detach and shed the biofilm-forming bacteria into the nutrient broth.

Step V: $1 \mathrm{~mL}$ of the biofilm formed bacteria from step IV was inoculated in sterile nutrient agar plate by spread plate method along with the biofilm-forming bacteria from the control tubes which are without the disinfectant. The inoculated plates were kept for incubation at $37^{\circ} \mathrm{C}$ overnight. The plates were observed and the total number of bacterial colonies was counted respective with the disinfectants and different time durations along with the control. The colony-forming units (CFUs) were counted by means of deep vision colony counter (AGS Scientific Company, Chennai, India). The sample culture plates for $S$. aureus are viewed from Figures $1 A, 2 A, 3 A, 4 A, 5 A$, and 6A. With respect to viridians Streptococcus species, the sample culture plates are viewed from Figures 1B, 2B, 3B, 4B, 5B, and 6B.

\section{Results}

Table 3 shows the mean and standard deviation of the disinfection potential of various disinfectants on $S$. aureus for three different time durations (10, 20, and 30 minutes).

For the 10-minute disinfection time, the number of CFUs were $150,385,5,140,630$, and 197 for $1 \%$ sodium hypochlorite,
$2 \%$ chlorhexidine, $2 \%$ glutaraldehyde, $3.8 \%$ sodium perborate, $2 \%$ aalam extract, and $2 \%$ neem extract, respectively. For the 20-minute disinfection time, the number of CFUs were 120,108, $3,41,278$, and 158 for $1 \%$ sodium hypochlorite, $2 \%$ chlorhexidine, $2 \%$ glutaraldehyde, $3.8 \%$ sodium perborate, $2 \%$ aalam extract, and $2 \%$ neem extract, respectively. For 30-minute disinfection time, the number of CFUs were $9,79,2,13,65$, and 29 for $1 \%$ sodium hypochlorite, $2 \%$ chlorhexidine, $2 \%$ glutaraldehyde, $3.8 \%$ sodium perborate, $2 \%$ aalam extract, and $2 \%$ neem extract, respectively.

Table 4 shows the mean and standard deviation of the disinfection potential of various disinfectants on viridians Streptococcus for three different time durations (10,20, and 30 minutes).

For 10-minute disinfection time, the number of CFUs were $175,441,5,13,457$, and 169 for $1 \%$ sodium hypochlorite, $2 \%$ chlorhexidine, $2 \%$ glutaraldehyde, $3.8 \%$ sodium perborate, $2 \%$ aalam extract, and $2 \%$ neem extract, respectively. For 20-minute disinfection time, the number of CFUs were 102, 205, 2, 6, 261, and 102 for $1 \%$ sodium hypochlorite, $2 \%$ chlorhexidine, $2 \%$ glutaraldehyde, $3.8 \%$ sodium perborate, $2 \%$ aalam extract, and $2 \%$ neem extract, respectively. For 30-minute disinfection time, the number of CFUs were $11,35,1.5,4,54$, and 44 for $1 \%$ sodium hypochlorite, $2 \%$ chlorhexidine, $2 \%$ glutaraldehyde, $3.8 \%$ sodium perborate, $2 \%$ aalam extract, and $2 \%$ neem extract, respectively.

Two-way ANOVA test was applied to find out whether any variations exist in the disinfectant potential of various disinfectants as well as their disinfection potential based on time durations $(10,20$, and 30 minutes) as revealed by the number of CFUs (Tables 5 and 6).

Since wide variations were present in the data, the data were converted to logarithmic scale before applying ANOVA test. The significant $p$ value of the interaction effect between the disinfection and time infers that the number of CFUs are statistically different, i.e., the average CFUs were different for the various disinfectants and for the different time periods. This is also shown in graphical representation (Figs 7 and 8 ).

With regard to biofilm-forming $S$. aureus, the Scheffe's post hoc test results (Table 5 ) indicate that $2 \%$ glutaraldehyde showed less number of CFUs compared to all other disinfectants in all the three time periods, namely 10,20 , and 30 minutes. Next to $2 \%$ glutaraldehyde, $1 \%$ sodium hypochlorite, and $3.8 \%$ sodium perborate exhibited good disinfection potential as exhibited by minimal CFUs when compared to $2 \%$ neem extract and $2 \%$ chlorhexidine. The least disinfectant potential was exhibited by $2 \%$ aalam extract. 

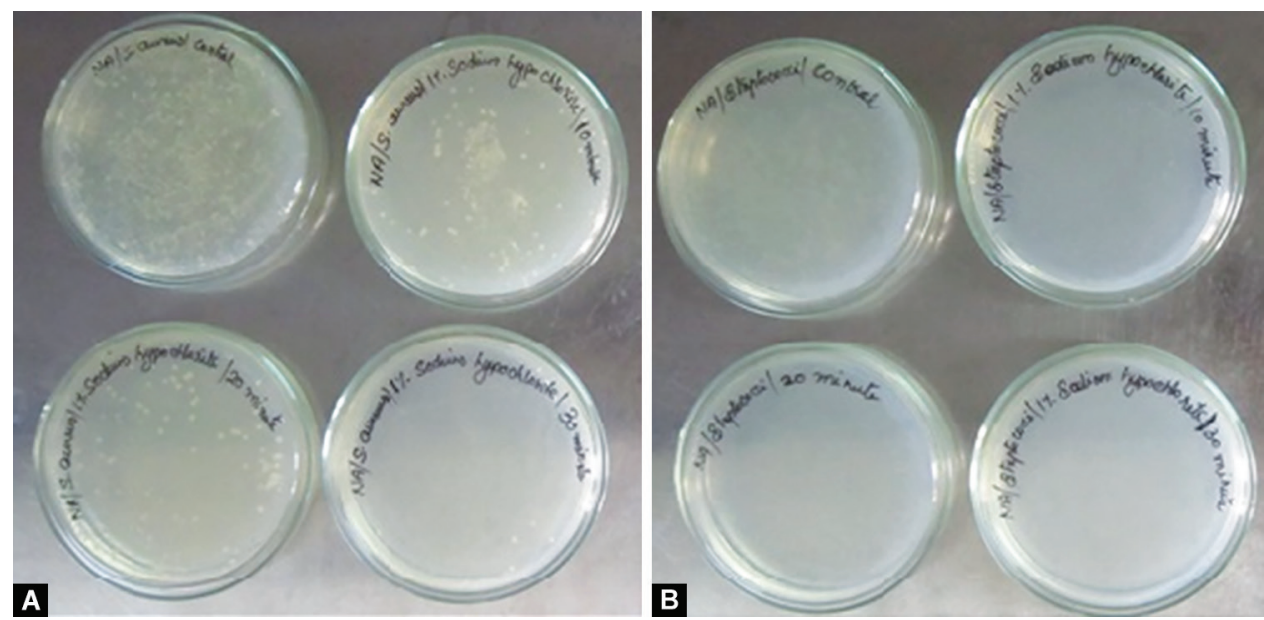

Figs $1 \mathrm{~A}$ and B: 1\% sodium hypochlorite on Staphylococcus aureus and viridians Streptococcus species for 10, 20, and 30 minutes
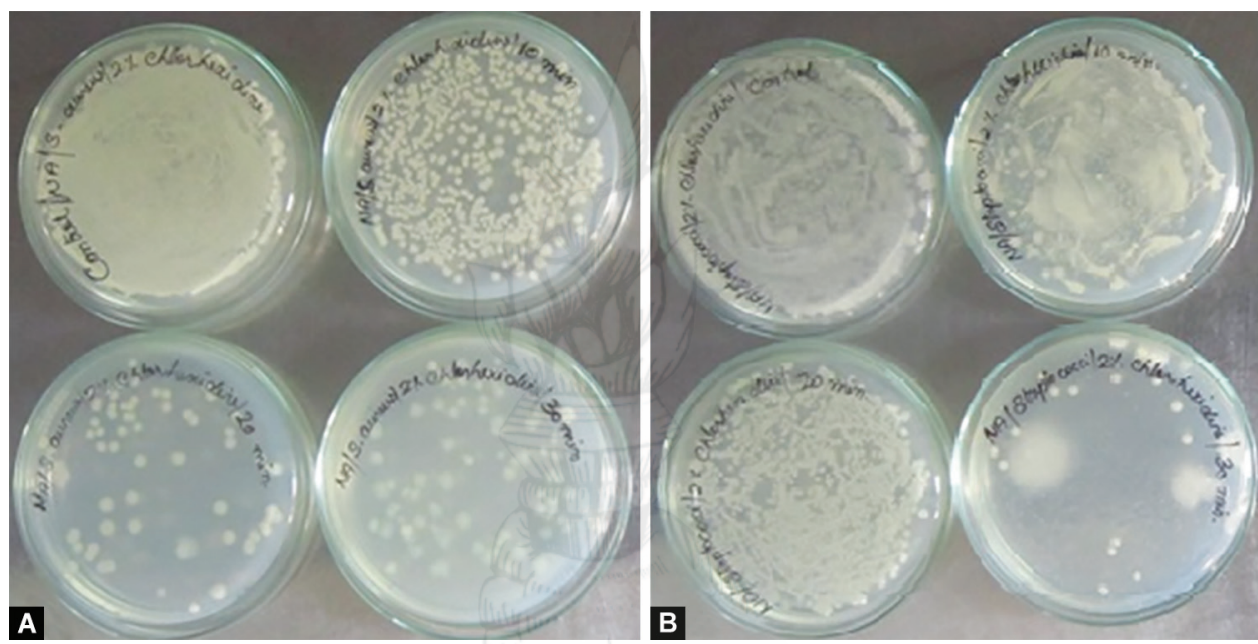

Figs 2A and B: 2\% chlorhexidine gluconate on Staphylococcus aureus and viridians Streptococcus species for 10, 20, and 30 minutes
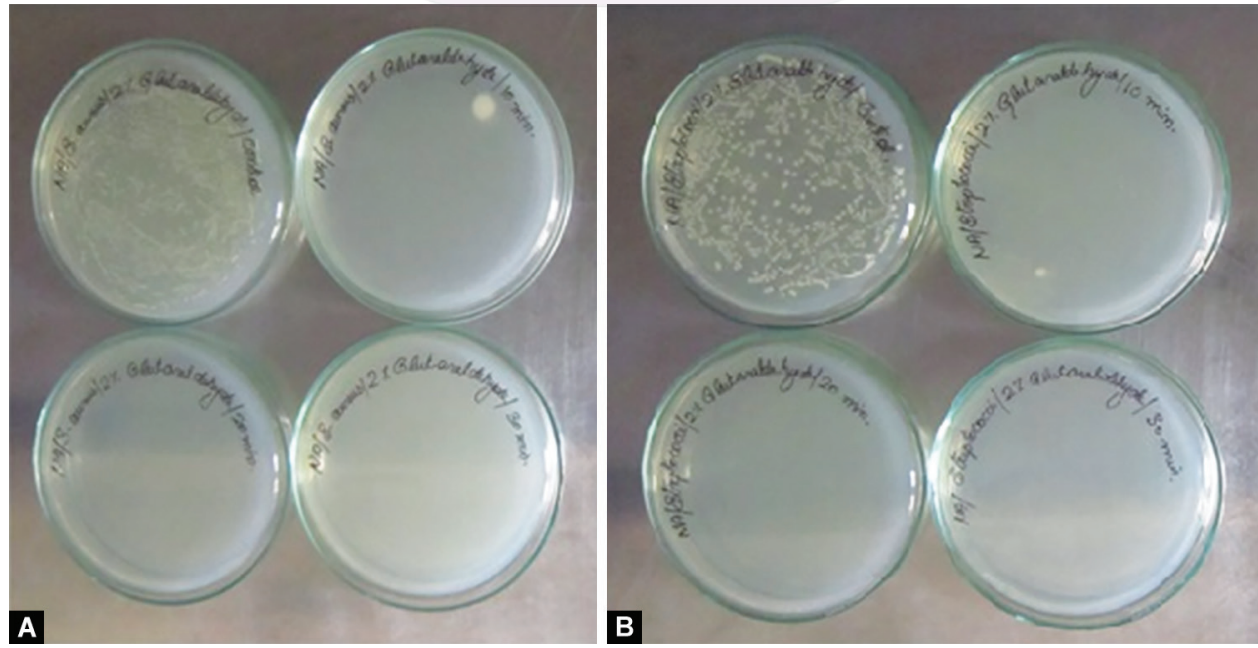

Figs $3 \mathrm{~A}$ and B: 2\% glutaraldehyde on Staphylococcus aureus and viridians Streptococcus species for 10, 20, and 30 minutes 

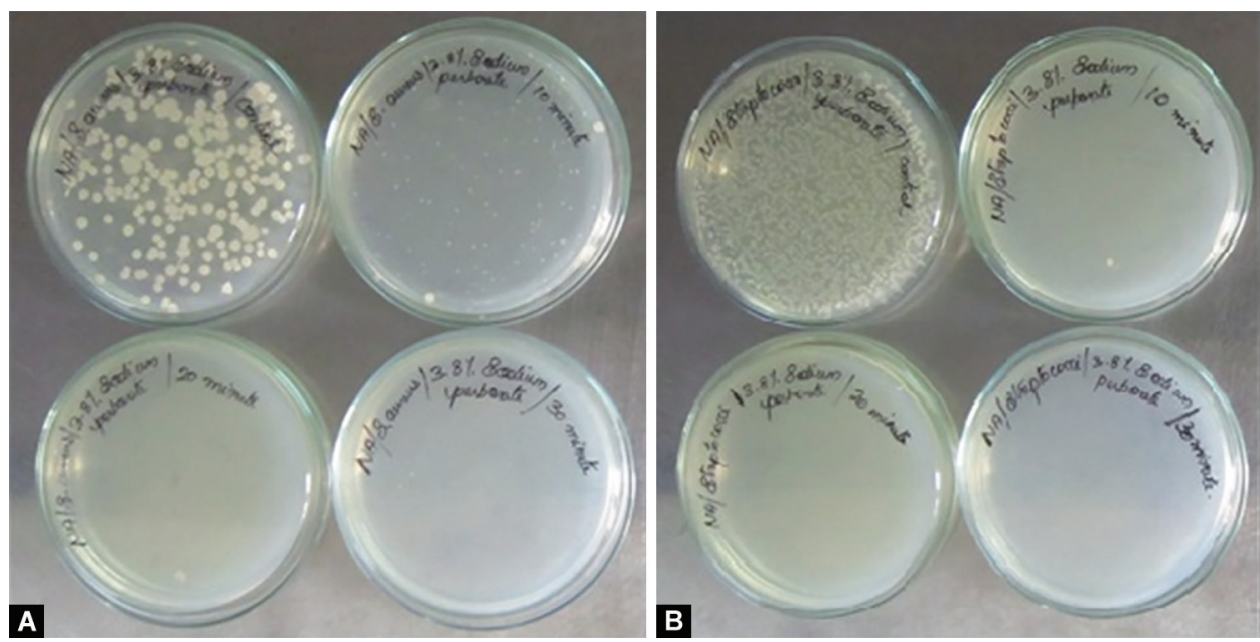

Figs 4A and B: 3.8\% sodium perborate on Staphylococcus aureus and viridians Streptococcus species for 10, 20, and 30 minutes
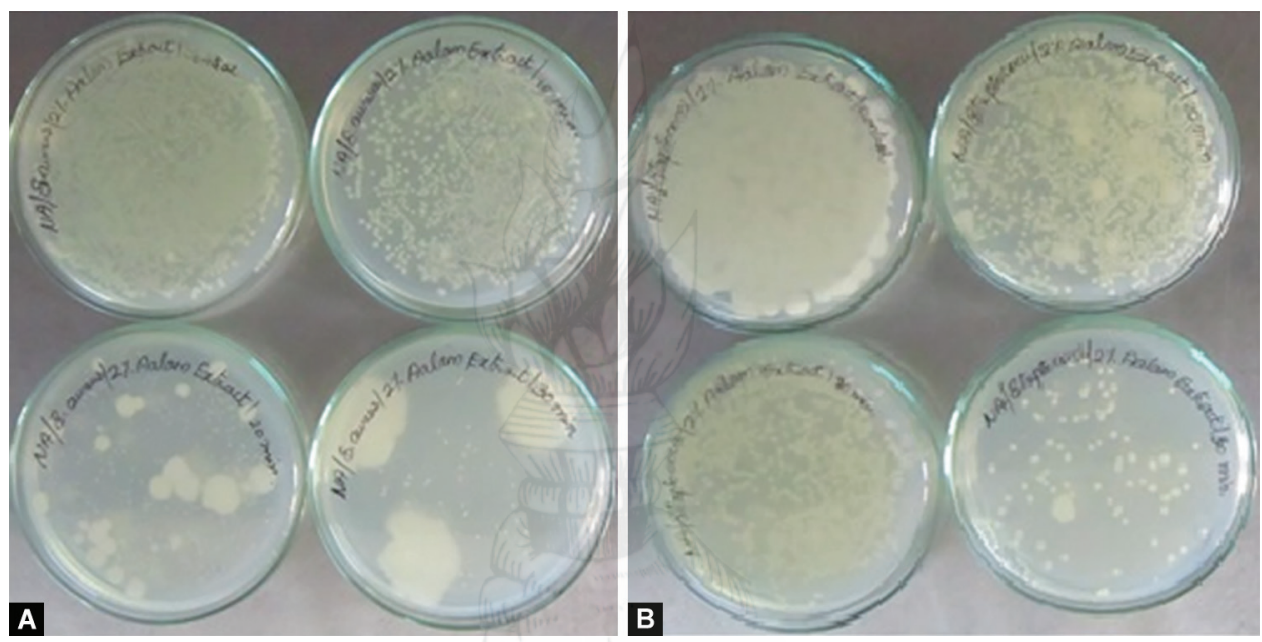

Figs 5A and B: 2\% aalam extract on Staphylococcus aureus and viridians Streptococcus species for 10, 20, and 30 minutes
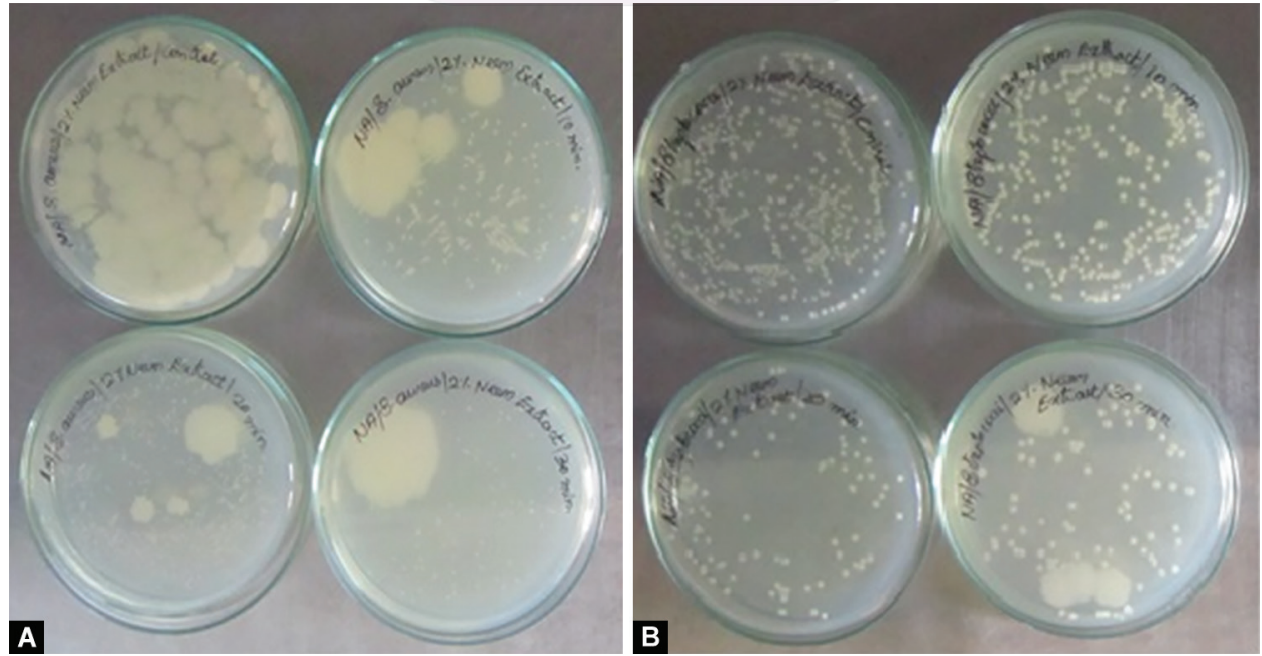

Figs 6 A and B: $2 \%$ neem extract on Staphylococcus aureus and viridians Streptococcus species for 10, 20, and 30 minutes 
Table 3: Disinfection activity over Staphylococcus aureus for different time durations (10, 20, and 30 minutes)

\begin{tabular}{|c|c|c|c|c|c|c|}
\hline \multirow[b]{3}{*}{ Disinfectants } & \multicolumn{6}{|c|}{ Staphylococcus aureus } \\
\hline & \multicolumn{2}{|c|}{10 minutes } & \multicolumn{2}{|c|}{20 minutes } & \multicolumn{2}{|c|}{30 minutes } \\
\hline & Mean & $S D$ & Mean & $S D$ & Mean & $S D$ \\
\hline $1 \%$ sodium hypochlorite & 150.167 & 15.9802 & 119.833 & 15.1712 & 9 & 3.0984 \\
\hline $2 \%$ chlorhexidine & 385.167 & 135.3624 & 107.667 & 53.4291 & 78.833 & 57.5201 \\
\hline $2 \%$ glutaraldehyde & 4.833 & 3.9707 & 2.667 & 1.3663 & 2 & 0.8944 \\
\hline $3.8 \%$ sodium perborate & 141.833 & 35.386 & 40.667 & 13.5892 & 13.167 & 6.5243 \\
\hline $2 \%$ aalam extract & 630.167 & 109.3808 & 278.333 & 169.0168 & 65 & 25.4951 \\
\hline $2 \%$ neem extract & 196.833 & 35.2444 & 157.833 & 39.2959 & 29 & 23.7908 \\
\hline
\end{tabular}

Table 4: Disinfection activity over Staphylococcus aureus for different time durations (10, 20, and 30 minutes)

\begin{tabular}{|c|c|c|c|c|c|c|}
\hline \multirow[b]{3}{*}{ Disinfectants } & \multicolumn{6}{|c|}{ Viridans Streptococcus } \\
\hline & \multicolumn{2}{|c|}{10 minutes } & \multicolumn{2}{|c|}{20 minutes } & \multicolumn{2}{|c|}{30 minutes } \\
\hline & Mean & $S D$ & Mean & $S D$ & Mean & $S D$ \\
\hline $1 \%$ sodium hypochlorite & 175.333 & 29.7635 & 101.5 & 14.6663 & 11 & 2.7568 \\
\hline $2 \%$ chlorhexidine & 440.667 & 271.9255 & 205 & 90.7833 & 34.5 & 25.1615 \\
\hline $2 \%$ glutaraldehyde & 4.833 & 1.8348 & 1.833 & 0.7528 & 1.5 & 0.5477 \\
\hline $3.8 \%$ sodium perborate & 13.167 & 7.1949 & 6.167 & 2.0412 & 3.667 & 1.8619 \\
\hline $2 \%$ aalam extract & 456.667 & 57.6773 & 260.833 & 65.1473 & 54.167 & 31.6886 \\
\hline $2 \%$ neem extract & 169.167 & 23.3274 & 101.667 & 20.4124 & 43.5 & 17.5926 \\
\hline
\end{tabular}

Table 5: Two-way ANOVA test result for log values (Staphylococcus aureus)

\begin{tabular}{llll}
\hline & & & $\begin{array}{l}\text { Scheffe post hoc test } \\
\text { values }\end{array}$ \\
\hline Disinfection & Fvalues & $p$ & \multicolumn{1}{c}{ valu } \\
Time & 205.4 & $<0.001$ & $3<1,4<6,2<5$ \\
Disinfection $\times$ time & 179.8 & $<0.001$ & $10>20>30$ \\
\hline
\end{tabular}

Table 6:Two-way ANOVA test result for log values (viridans Streptococccus)

\begin{tabular}{|c|c|c|c|}
\hline Source & Fvalues & $p$ & $\begin{array}{l}\text { Scheffe post hoc test } \\
\text { values }\end{array}$ \\
\hline Disinfection & 364.7 & $<0.001$ & $3<4<1,6,2<5$ \\
\hline Time & 212.8 & $<0.001$ & $10>20>30$ \\
\hline Disinfection $\times$ time & 7.5 & $<0.001$ & \\
\hline
\end{tabular}

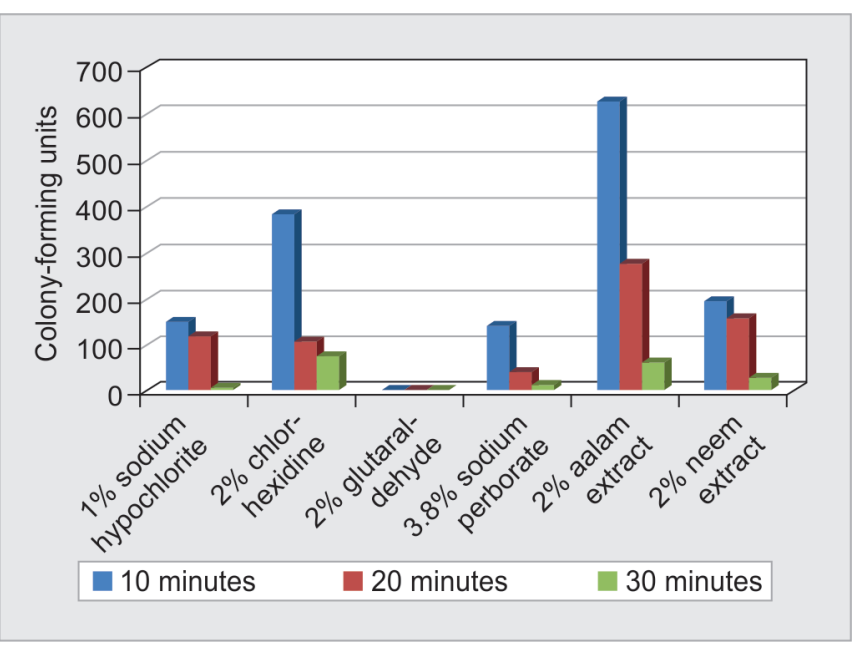

Fig. 7: Colony-forming units of Staphylococcus aureus after disinfection for various periods of time
With regard to biofilm-forming viridans Streptococcus the Scheffe's post hoc test results (Table 6) indicate that 2\% glutaraldehyde showed less number of CFUs compared to all other disinfectants in all the three time periods, namely 10,20, and 30 minutes. Next to $2 \%$ glutaraldehyde, $3.8 \%$ sodium perborate exhibited good disinfection potential exhibited by minimal CFUs and this was followed by $1 \%$ sodium hypochlorite when compared to $2 \%$ neem extract and $2 \%$ chlorhexidine. The least disinfectant potential was exhibited by $2 \%$ aalam extract.

\section{Discussion}

Sodium hypochlorite is not recommended to disinfect the dentures because of its bleaching effect on acrylic denture base. ${ }^{7}$ Some authors have described the antibacterial efficacy of $1 \%$ sodium hypochlorite. ${ }^{8,9}$ However, in the present study, $1 \%$ sodium hypochlorite has been used as a disinfectant. Some authors have reported the antimicrobial effectiveness of $1 \%$ sodium hypochlorite against Streptococcus mutans and S. aureus on acrylic resin specimens. ${ }^{10}$ In the present study, sodium hypochlorite showed less denture disinfection efficacy when compared to $2 \%$ glutaraldehyde.

In a study by Orsi et al., $11 \%$ sodium hypochlorite, $2 \%$ sodium hypochlorite, and $2 \%$ glutaraldehyde were used to disinfect bacterial strains, namely S. aureus, S. mutans, Pseudomonas aeruginosa, and Enterococcus faecalis. It was found that for 5 and 10 minutes immersion, $2 \%$ glutaraldehyde was more effective than $2 \%$ sodium hypochlorite. Their finding is much similar to the results of this study.

In the present study, 1\% sodium hypochlorite showed similar antibacterial effect against $S$. aureus as $3.8 \%$ sodium perborate. When it comes to viridans Streptococcus species, $1 \%$ sodium hypochlorite exhibited less antibacterial efficacy when compared to both $2 \%$ glutaraldehyde and $3.8 \%$ sodium perborate.

In a similar study by Balaji et al., ${ }^{12} 2 \%$ glutaraldehyde, $1 \%$ sodium hypochlorite, and $2 \%$ chlorhexidine gluconate were utilized to disinfect acrylic strips contaminated with Streptocococcus mutans. 


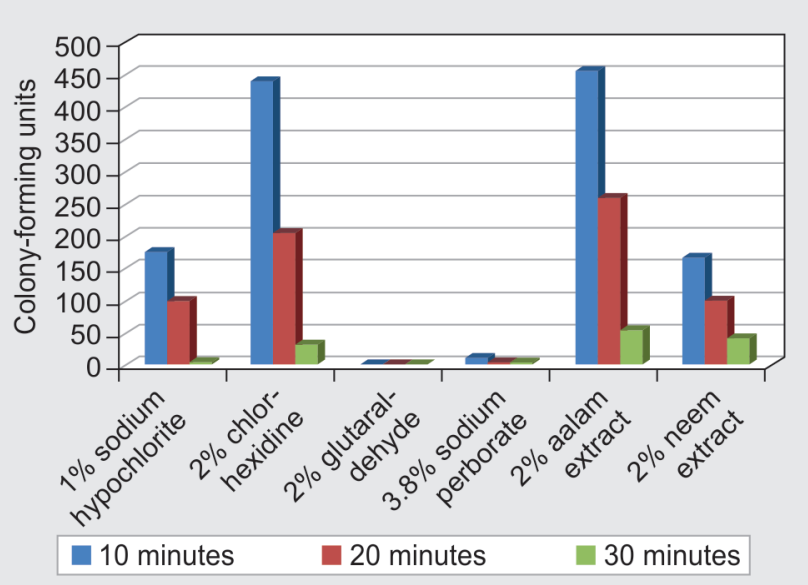

Fig. 8: Colony-forming units of viridians Streptococcus after disinfection for various periods of time

In contrast to the present study, it was found that $1 \%$ sodium hypochlorite was a better disinfectant when compared to $2 \%$ glutaraldehyde and $2 \%$ chlorhexidine gluconate.

Pavarina et al. reported that $4 \%$ chlorhexidine gluconate exhibited reasonable disinfection capacity after 10 minutes when compared to $1 \%$ sodium hypochlorite. ${ }^{13}$ But in this study, $2 \%$ chlorhexidine gluconate exhibited poor disinfection efficacy among the synthetic disinfectants against both the groups of bacteria.

With regard to $2 \%$ glutaraldehyde, several authors have advised for extended time of immersion of dentures (more than 5 minutes) to achieve optimum antibacterial efficacy. ${ }^{14-16}$ In the present study, disinfection was achieved even after 10 minutes of immersion as in accordance with previous studies. Among the synthetic disinfectants, it was obvious $2 \%$ glutaraldehyde has the best disinfection efficacy.

The aerial root extract of $F$. benghalensis (aalam tree) has been shown to exhibit antibacterial properties against $S$. mutans, S. aureus, Klebsiella pneumoniae, and E. coli. ${ }^{17-19}$ In the present study, methanol extract of aerial roots of $F$. benghalensis exhibited poor disinfection against both biofilm-forming S. aureus and viridans Streptococcus.

Neem extracts have been known to exhibit antibacterial properties ${ }^{20,21}$ against S. mutans and S. aureus. In the present study, $2 \%$ methanolic extract of neem tree bark exhibited better antibacterial efficacy against the two groups of bacteria when compared to $2 \%$ chlorhexidine gluconate. $2 \%$ neem extract revealed similar disinfection abilities when compared to $2 \%$ sodium hypochlorite against biofilm-forming viridans Streptococcus.

The results of the present study differ from various previous studies as the biofilm-forming bacteria are more resistant to disinfectants when compared to the free planktonic bacteria present in vivo as indicated by Theraud et al. ${ }^{22}$

In the present study, biofilms of both $S$. aureus and viridans Streptococcus species of O.D. values of more than 1.5. This could give an idea of the poor disinfection effect of $2 \%$ chlorhexidine gluconate and $2 \%$ methanolic extract of aalam with regard to strongly biofilmforming S. aureus and viridians Streptococcus species isolates.

A promising factual in the present study is that $2 \%$ methanolic extract of neem is viable alternative natural disinfectant which has comparable disinfection ability as $1 \%$ sodium hypochlorite for both the biofilm-forming bacteria.
The other interesting find in the present study is that the disinfectants used showed better disinfections with increase in time duration from 10 minutes to 30 minutes with respect to all the disinfectants used.

A 10-minute disinfection for S. aureus was best achieved by $2 \%$ glutaraldehyde, whereas 10-minute disinfection for viridians Streptococcus species was best achieved by both $2 \%$ glutaraldehyde and $3.8 \%$ sodium perborate.

The present study has a few limitations namely: the concentration of the disinfectants, i.e., only one concentration per disinfectant, time duration (restricted to 10, 20, 30 minutes), and sample size of the strong biofilm-forming bacteria (restricted to six for each bacteria). The sample size was restricted to six as disinfection procedures were done in triplicate.

In the present study, minimal and recommended concentrations of various studies were used to achieve the disinfection of the strongly biofilm-forming bacteria. The reason for adapting this method of disinfection is to prevent damage of the acrylic resin while immersion disinfection as well as avoidance of tissue irritation and systemic side effects of the residual disinfectants on the denture base acrylic surface.

It is well-established that as time and concentrations of the disinfectants are increased disinfection efficacy will be markedly increased. But the disinfectant efficacy should be adopted keeping in mind the following factors, namely nature of biofilm, concentration of the disinfectant minimal damage to acrylic surface, duration of disinfection, and local and systemic side effects of the residual disinfectant on the denture acrylic surface.

A judicious choice have to made while choosing the disinfectant keeping in mind the above said factors and also by adopting adequate protocols ${ }^{1}$ for the well-being of the patient and condition of the prosthesis.

\section{CONCLUSION}

For biofilm-forming S. aureus, 2\% glutaraldehyde showed best antibacterial efficacy which was followed by $1 \%$ sodium hypochlorite and $3.8 \%$ sodium perborate. When it comes to biofilmforming viridans streptococcal species, $2 \%$ glutaraldehyde showed best antibacterial efficacy. Next to $2 \%$ glutaraldehyde, $3.8 \%$ sodium perborate exhibited good disinfection potential based on minimal CFUs. For both the biofilm-forming bacteria, least disinfectant potential was exhibited by $2 \%$ aalam extract. An interesting finding in the study is the disinfection potential of $2 \%$ neem bark extract which was similar to $1 \%$ sodium hypochlorite disinfection efficacy for both biofilm-forming S. aureus and viridians streptococcal species. Hence, $2 \%$ neem could be used as a natural alternative for chemical denture disinfectants.

\section{References}

1. Felton D, Cooper L, Duqum I, et al. Evidence based guidelines for the care and maintenance of complete denture. J Am Dent Assoc 2011;142(Suppl 1):1S-20S. DOI: 10.14219/jada.archive.2011.0067.

2. Salles MM, Badaró MM, Arruda CN, et al. Antimicrobial activity of complete denture cleanser solutions based on sodium hypochlorite and Ricinus communis-a randomized clinical study. J Appl Oral Sci 2015;23(6):637-642. DOI: 10.1590/1678-775720150204.

3. Connor JN, Schoenfeld CM, Taylor RL. An evaluation of an enzyme denture cleanser. J Prosthet Dent 1977;37(2):147-157. DOI: 10.1016/0022-3913(77)90236-0.

4. Lee HE, Lee CY, Chang HW, et al. Effects of different denture cleaning methods to remove Candida albicans from acrylic resin denture based material. J Dent Sci 2011;6(4):216-223. DOI: 10.1016/j.jds.2011.09.006. 
5. Maris P. Mode of action of disinfectants. Rev Sci Tech 1995;14(1):47-55. DOI: $10.20506 /$ rst.14.1.829.

6. Barnabé W, de Mendonça Neto T, Pimenta FC, et al. Efficacy of sodium hypochlorite and coconut soap used as disinfecting agents in the reduction of denture stomatitis, Streptococcus mutans and Candida albicans. J Oral Rehabil 2004;31(5):453-459. DOI: 10.1111/j.13652842.2004.01254.x

7. Webb BC, Thomas CJ, Harty DWS, et al. Effectiveness of two methods of denture sterilization. J Oral Rehabil 1998;25(6):416-423. DOI: 10.1046/j.1365-2842.1998.00266.x.

8. Salvia ACRD, Matilde FDS, Rosaetal FCS. Disinfection protocols to prevent cross-contamination between dental offices and prosthetic laboratories. J Infect Public Health 2013;6(5):377-382. DOI: 10.1016/ j.jiph.2013.04.011.

9. Chau VB, Saunders TR, Pimsler M, et al. Indepth disinfection of acrylic resins. J Prosthet Dent 1995;74(3):309-313. DOI: 10.1016/S00223913(05)80140-4

10. da Silva FC, Kimpara ET, Mancini MNG, et al. Effectiveness of six different disinfectants on removing five microbial species and effects on the topographic characteristics of acrylic resin. J Prosthodon 2008;17(8):627-633. DOI: 10.1111/j.1532-849X.2008.00358.x.

11. Orsi IA, Junior $A G$, Villabona $C A$, et al. Evaluation of the efficacy of chemical disinfectants for disinfection of heat-polymerized acrylic resin. Gerodontology 2011;28(4):253-257. DOI: 10.1111/j.17412358.2010.00400.x.

12. Balaji S, Muralidharan NP. Effectiveness of 4 different disinfectants in removing 2 microorganisms from acrylic resins. Int J Pharm Sci Rev Res 2016;40(2):83-85.

13. Pavarina AC, Pizzolitton AC, Machado A, et al. An infection control protocol: effectiveness of immersion solutions to reduce the microbial growth on dental prostheses. J Oral Rehabil 2003;30(5): 532-536. DOI: 10.1046/j.1365-2842.2003.01093.x.
14. Bhathal MK, Kukreja U, Kukreja N. Evaluation of efficacy of different denture disinfectants on biofilms formed on acrylic resin. Dent J Adv Stud 2018;6:20-27. DOI: 10.1055/s-0038-1671696.

15. Henderson CW, Schwartz RS, Herbold ET, et al. Evaluation of the barrier system, an infection control system for the dental laboratory. J Prosthet Dent 1987;58(4):517-521. DOI: 10.1016/0022-3913(87) 90286-1.

16. Jnanadev KR, Satish Babu CL. Disinfecting the acrylic resin plate using electrolyzed acid water and $2 \%$ glutaraldehyde. A comparative microbiological study. J Indian Prosthodont Soc 2011;11(1):36-44. DOI: 10.1007/s13191-011-0057-x.

17. Prashanth KI, Cecilia SM, Jayalakshmi RK, et al. A study on in vitro antibacterial activity of $F$. benghalensis linn. On dental caries pathogens Streptococcus mutans and actinomyces viscosus $\mathrm{f}$. Michael Bernard. Int J Pharm Sci Res 2013;4(2):843-846.

18. Parameswari SA, Chetty M, Sekar C. Phytochemical studies and antibacterial activity of aerial root of $F$. benghalensis. Int J Res Phytochem Pharmacol 2011;1:83-87.

19. Singh RK, Watal G. Antimicrobial potential of $F$. benghalensis aerial roots. Int J Pharma Bio Sci 2010;1(3):1-9.

20. Wolinsky LE, Mania S, Nachnani S, et al. The inhibiting effect of aqueous Azadirachta indica (Neem) extract upon bacterial properties influencing in vitro plaque formation. J Dent Res 1996;75(2):816-822. DOI: $10.1177 / 00220345960750021301$.

21. Vanka A, Tandon S, Rao SR, et al. The effect of Indigenous Neem (Azadirachta indica) mouth wash on S. mutans and Lactobacilligrowth. Indian J Dent Res 2001;12(3):133-144.

22. Theraud M, Bedouin Y, Guiguen C, et al. Efficacy of antiseptics and disinfectants on clinical and environmental yeast isolates in planktonic and biofilm conditions. J Med Microbiol 2004;53(Pt 10):1013-1018. DOI: 10.1099/jmm.0.05474-0. 